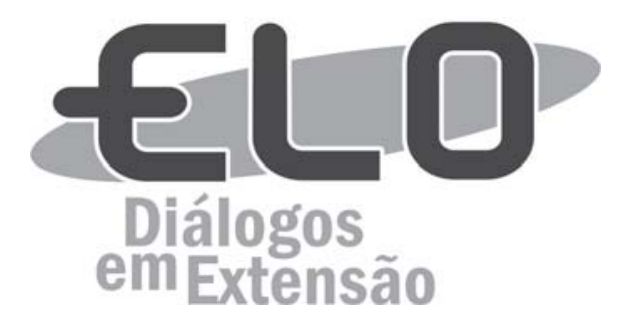

\title{
Gênero, raça e participação: percepção de discentes do Ensino Médio acerca da sustentabilidade
}

\author{
Letícia Silva Ferreira ${ }^{1}$, Viviane Santos Pereira ${ }^{2}$ Vera Simone Schaefer Kalsing ${ }^{3}$
}

\begin{abstract}
Resumo: Este relato de experiência apresenta os desdobramentos de uma roda de conversa ocorrida em uma escola estadual de Lavras-MG. Objetivava-se com essa atividade promover entre os (as) discentes da referida instituição, a reflexão sobre os temas que também permeiam a sustentabilidade quais sejam, gênero e raça. A partir do vídeo "A História das Coisas", buscou-se pela problematização entre os (as) discentes de como as mulheres negras encontram-se excluídas dos processos de decisão na sociedade brasileira, uma vez que essas não atuam ativamente no processo de aquisição de bens e acumulação de capital sugerida pelo sistema capitalista em que estamos inseridos. Observou-se que realmente ainda há a percepção equivocada de que desenvolvimento sustentável está diretamente relacionado à reciclagem e economia de recursos naturais, e que a equidade nas relações sociais não é compreendida como parte de uma sociedade sustentável.
\end{abstract}

Palavras-chave: Desenvolvimento sustentável. Gênero. Raça. Participação.

Área Temática: Gênero

\section{Gender, race and participation: perception of secondary school students about sustainability}

Abstract: This report of experience presents the unfolding of a conversation wheel that happened in a state school of Lavras-MG. The purpose of this activity was to promote among the students of the mentioned institution, the reflection on the themes that also permeate sustainability, being, gender and race. From the video "The History of Things", we sought the problematization among the students of how black women are excluded from the decision processes in brazilian society, since they do not actively act in the acquisition process of capital goods and accumulation suggested by the capitalist system in which we are inserted. It was observed that there is still a misperception that sustainable development is directly related to the recycling and saving of natural resources, and that equity in social relations is not understood as part of a sustainable society.

Keywords: Sustainable development. Gender. Race. Participation.

\section{Género, raza y participación: percepción de los discentes de la Enseñanza Media acerca de la sostenibilidad}

Resumen: Este relato de experiencia presenta los desdoblamientos de una rueda de conversación ocurrida en una escuela estatal de Lavras-MG. Se pretendía con esta actividad promover entre los (los) discentes de la referida institución, la reflexión sobre los temas que también permean la sustentabilidad cuáles sean, género y raza. A partir del video "La Historia de las Cosas", se buscó por la problematización entre los discursos de cómo las mujeres negras se encuentran excluidas de los procesos de decisión en la sociedad brasileña, una vez que éstas no actúan activamente en el proceso de adquisición de bienes y acumulación

\footnotetext{
${ }^{1}$ Universidade Federal de Lavras. Rua Dr. João Pizzolante, 7 Apt. 201, Jardim Fabiana, Lavras-MG CEP: 37.200-000, (035)99754-1982, leticiaferreira@nedi.ufla.br ${ }^{2}$ Universidade Federal de Lavras - DAE/UFLA (orientação) - vivianepereira@dae.ufla.br

${ }^{3}$ Universidade Federal de Lavras - DCH/UFLA (orientação) - vera.kalsing@dch.ufla.br
} 
de capital sugerida por el sistema capitalista en que estamos insertos. Se observó que realmente todavía existe la percepción equivocada de que el desarrollo sostenible está directamente relacionado con el reciclaje y la economía de recursos naturales y que la equidad en las relaciones sociales no se entiende como parte de una sociedad sostenible.

Palabras clave: Desarrollo sostenible. Género. Raza. Participación.

\section{Introdução}

Este relato de experiência apresenta os resultados de uma roda de conversa que procurou problematizar questões de gênero, raça, sustentabilidade e participação dentro de uma escola estadual no sul de Minas Gerais, a fim de promover a reflexão entre os (as) discentes sobre a importância das relações igualitárias como forma de promover um desenvolvimento sustentável.

A escolha pelos temas que orientaram a realização da roda de conversa se deu em virtude de se perceber, após a experiência como professora da educação básica, que existe entre os (as) discentes a ideia equivocada de que o desenvolvimento sustentável está diretamente relacionado à reciclagem e à economia de recursos naturais, e que a equidade nas relações sociais não é compreendida como parte de uma sociedade sustentável.

A proposta surgiu a partir das vivências em uma disciplina intitulada "Desenvolvimento Sustentável e Meio Ambiente", ministrada pela Professora Doutora Viviane Santos Pereira. Tal disciplina integra a matriz curricular do Programa de Pós-Graduação em Desenvolvimento Sustentável e Extensão (PPGDE), ofertado pelo Departamento de Administração e Economia (DAE) da Universidade Federal de Lavras (UFLA). Nessa disciplina, muitos temas relacionados ao desenvolvimento sustentável balizaram as discussões e, como produto final foi solicitado um relato de alguma experiência envolvendo um dos temas que circundam a temática da sustentabilidade.

Como mencionado anteriormente, os temas que permearam a roda de conversa versaram sobre gênero, raça, sustentabilidade e participação. A sustentabilidade e a participação foram amplamente discutidas na disciplina geradora da atividade. Porém, as questões de gênero e raça, que também impulsionaram a proposta, encontram-se como centro das discussões do Grupo de Estudos sobre Gênero e Raça, coordenado pela Professora Doutora Vera Simone Schaefer Kalsing, do Departamento de Ciências Humanas (DCH) e também professora do PPGDE. A partir das discussões ocorridas nesse grupo de estudos, foi possível observar que as mulheres negras brasileiras, em expressiva maioria, encontram-se em uma situação de vulnerabilidade econômica e social, sendo impedidas de atuarem de maneira igualitária entre os mais diversos segmentos de nossa sociedade, o que nesse sentido, reforça a urgência das discussões que orientaram a realização da roda de conversa na escola.

Embasaram teoricamente essa roda de conversa o texto de Veiga (2005) sobre o que é desenvolvimento, Bordenave (1994) acerca da participação, o livro de Florestan Fernandes "A integração do negro na sociedade de classes" (2008) que apresenta o processo de exclusão social a que o (a) negro (a) brasileiro (a) foi exposto (a) após a abolição da escravatura e o texto de Góis (2008) que relata o processo diferenciado de inserção da mulher negra na universidade.

Como resultados de uma roda de conversa, o relato de tal experiência não deve ser compreendido como um fim em si mesmo, mas como possibilidade de reflexão acerca da urgência da inserção dos temas mencionados anteriormente no ambiente escolar, a fim de se promover relações mais justas e igualitárias em nossa sociedade.

\section{Objetivos}

O principal objetivo da roda de conversa foi o de promover a reflexão em torno de questões que também permeiam o desenvolvimento sustentável, que não são somente baseadas em fatores ambientais e econômicos, mas também sociais, como as relações de equidade entre os indivíduos.

Especificamente, procurou-se pela compreensão de como os (as) estudantes que participaram da roda de conversa compreendem o desenvolvimento sustentável e quais as suas percepções acerca da inclusão de mulheres negras nos segmentos sociais, econômicos e culturais de nossa sociedade. 


\title{
Metodologia
}

A roda de conversa ocorreu no dia 22 de junho de 2017 na Escola Estadual Cristiano de Souza no município de Lavras-MG entre os (as) estudantes do $2^{\circ}$ e $3^{\circ}$ anos do Ensino Médio. A seleção das turmas que iriam integrar o evento ficou a cargo da direção e coordenação da escola que não mediram esforços para que todos os procedimentos necessários para a realização do evento fossem executados, tais como, reserva de espaço, organização de materiais audiovisuais e agendamento com professores (as) e estudantes.

Como professora da educação básica, as ações foram pensadas a partir do âmbito escolar por acreditar ser esta uma instância promotora de conhecimento e de reflexão sobre os problemas que circundam a sociedade. A escolha da instituição se deu em virtude de já haver trabalhado nessa escola durante todo o ano de 2016 e de se conhecer a urgência dos temas para a referida instituição de ensino. Como docente nessa instituição, muitas questões puderam ser observadas e dentre elas, a forte representação de discentes negros (as) sobre os docentes, a condição socioeconômica dos (as) estudantes, qual seja, todos de classe popular e a equivocada percepção de pertencimento, evidenciada por alguns episódios de vandalismo e depredação do espaço da escola.

Como estratégia para interação dos (as) estudantes, foi utilizado o espaço do auditório da instituição e as cadeiras foram dispostas em semicírculos para que a interação ocorresse de forma compartilhada. Aproximadamente 100 estudantes participaram do evento.

Por se tratar de um público jovem e por dispor de aproximadamente uma hora e trinta minutos para a realização do evento, foram utilizados recursos audiovisuais a fim de tornar o assunto mais prazeroso e de fácil assimilação. Após a apresentação pessoal da prelecionista da roda de conversa e da explanação dos objetivos do evento, iniciaram-se as instigações junto aos (às) discentes a partir da pergunta "O que é desenvolvimento sustentável?". Em seguida, utilizou-se o vídeo "The Story of Stuff", "A história das coisas", com o objetivo de apresentar a lógica mercadológica que rege o sistema capitalista de consumo no qual estamos inseridos (as) para, a partir de então, pensar nas maiores excluídas do processo de aquisição de bens e acumulação de capital de nossa sociedade: as mulheres negras.

Houve várias contribuições durante a apresentação do evento e, em sua grande maioria, de meninas. Somente um menino se manifestou.

\section{Resultados e Discussão}

Ao iniciar a roda de conversa pela pergunta "O que é desenvolvimento sustentável?" logo vieram as respostas que confirmaram as hipóteses iniciais. Das pessoas que quiseram participar, todas responderam pensar que sustentabilidade relaciona-se à economia de recursos naturais e à reciclagem do lixo, ou seja, não demonstraram reconhecer que as relações de equidade em sociedade constituemse um fator importante na busca por uma sociedade sustentável. Ao relatar acerca do desenvolvimento e de propor a reflexão sobre os conceitos equivocados, Veiga (2005) diz que

\begin{abstract}
(...). O desenvolvimento tem a ver, primeiro e acima de tudo, com a possibilidade de as pessoas viverem o tipo de vida que escolheram, e com provisão dos instrumentos e das oportunidades para fazerem as suas escolhas. E, ultimamente, o Relatório do Desenvolvimento Humano tem insistido que essa é uma ideia tão política quanto econômica. Vai desde a proteção dos direitos humanos até o aprofundamento da democracia. A menos que as pessoas pobres e marginalizadas possam influenciar ações políticas de âmbitos local e nacional, não é provável que obtenham acesso equitativo ao emprego, escolas, hospitais, justiça, segurança e outros serviços básicos, diz o atual administrador do PNUD, Mark Malloch Brown, em seu prefácio ao Relatório de 2004 (VEIGA, 2005, p.81).
\end{abstract}

Após evidenciar a existência de pessoas que se encontram em situações de vulnerabilidade em nossa sociedade, promoveu-se a reflexão em torno da participação e, nesse sentido, observou-se que há também equívocos em sua compreensão. Algumas respostas evidenciaram o falso entendimento de que as pessoas não participam por opção, por não quererem partilhar das decisões, por não aspirarem melhores condições de vida. Segundo seus entendimentos, se uma pessoa quer de fato alguma coisa, 
não existem fatores que lhe impeçam de conseguir, surgiram palavras como "boa vontade", "esforço" e "dedicação".

Para demonstrar o quanto a ausência de participação está diretamente relacionada ao sistema de consumo no qual estamos inseridos, Bordenave (1994) esclarece que esse na verdade é o grande responsável pelo processo de marginalização de alguns grupos. Segundo o autor

(...). O subdesenvolvimento de uns é provocado pelo "superdesenvolvimento" de outros. Para que alguns possam acumular vastos patrimônios, outros necessitam ser explorados e sacrificados. Para que o poder se concentre em poucas mãos, a participação política na maioria da população deve ser cortada.

Não há, pois, marginalidade mas marginalização.

Neste novo enfoque, a participação não mais consiste na recepção passiva dos benefícios da sociedade mas na intervenção ativa na sua construção, o que é feito através da tomada de decisões e das atividades sociais em todos os níveis (BORDENAVE, 1994 p. 20, grifo do autor).

É importante ressaltar aqui o que Bordenave compreende como marginalidade e marginalização. Segundo o autor, marginalidade consiste em um processo de deixar de fora ou às margens da tomada de decisão em algumas circunstâncias. Já a marginalização é promovida por forças intrínsecas a um desenvolvimento modernizador, que acaba por promover a desigualdade entre os grupos de determinada sociedade.

Nessa fase da discussão, foram apresentados questionamentos referentes à cor da pele dos que menos participam das ações políticas em nosso país, da forte representação da população negra em profissões socialmente desvalorizadas e da presença maciça de negros em situações de vulnerabilidade econômica e social. Florestan Fernandes (2008) quando discorre acerca da forma como os negros foram levados a se integrar na sociedade brasileira pós-abolição afirma que

A desagregação do regime escravocrata e senhorial se operou, no Brasil, sem que se cercasse a destituição dos antigos agentes de trabalho escravo de assistência e garantias que os protegessem na transição para o sistema de trabalho livre. Os senhores foram eximidos da responsabilidade pela manutenção e segurança dos libertos, sem que o Estado, a Igreja ou outra qualquer instituição assumissem encargos especiais, que tivessem por objeto prepará-los para o novo regime de organização da vida e do trabalho. O liberto se viu convertido, sumária e abruptamente, em senhor de si mesmo, tornandose responsável por sua pessoa e por seus dependentes, embora não dispusesse de meios materiais e morais para realizar essa proeza nos quadros de uma economia competitiva (FERNANDES, 2008, p. 29).

Fica evidente que os negros e negras brasileiros (as) tiveram grandes dificuldades em se encontrar dentro desse sistema de acumulação sugerido pelo capitalismo. Não dispunham de aparatos que lhes garantissem condições de igualdade para competir com brancos e brancas em uma sociedade que sugere a aquisição de bens e a acumulação de capital como prova de "desenvolvimento", e os resquícios dessa situação se refletem até nossos dias.

Buscou-se também demonstrar o quanto os negros, e em especial as negras brasileiras, encontramse marginalizadas pelo processo de exclusão promovido pelo sistema antes apresentado. Góis (2008) apresenta em seu texto que o acesso e a permanência de mulheres negras no ensino superior mostrase diferenciado em relação às mulheres brancas. As primeiras operam com uma série de fatores que juntos acabam por incluí-las em profissões menos valorizadas socialmente e, consequentemente, mal remuneradas. Novamente aqui nesse ponto da conversa, apesar de poucas participações, observou-se o não reconhecimento de que esses diferenciais existem. Certo conformismo pôde ser observado diante das questões apresentadas.

No decorrer da conversa, houve relatos de experiências dos quais somente duas moças negras quiseram relatar situações discriminatórias a que estiveram submetidas e nesse ponto surgiram também 
questões relacionadas à discriminação que mulheres negras sofrem nas redes sociais por ocuparem posições de destaque em meios artísticos, por exemplo. Nomes como os de Maria Júlia Coutinho (repórter), Taís Araújo (atriz) e Ludmilla (cantora) surgiram na conversa e uma aluna (branca) foi enfática ao afirmar: "Elas sofrem discriminação porque querem ser brancas!" Aqui, é possível refletir sobre o que está implícito em sua fala: em seu entendimento existem lugares para a mulher negra estar que, certamente, não é o mesmo da mulher branca.

Refletindo sobre o que Bordenave (1994) afirma ser a participação, que o autor diz ser essa uma intervenção ativa na construção das identidades dos sujeitos a partir da tomada de decisões em atividades sociais em todos os níveis e não somente a recepção passiva dos benefícios da sociedade, a roda de conversa foi finalizada com um chamado à participação de todos e todas em nossa sociedade.

\section{Conclusões}

Infelizmente, em países colonizados por homens brancos possuidores de uma ideologia de exploração como no Brasil, que por tanto tempo utilizou-se de mão de obra escrava africana, não é de se estranhar que os malefícios de tal processo sejam fortemente evidenciados sobre a população negra, e em especial sobre as mulheres negras.

Caminham juntamente a esses fatores, a noção deturpada de desenvolvimento que deve ser medido pela capacidade dos indivíduos de atuarem ativamente no processo de aquisição de bens e acumulação de capital, além da visão equivocada que determinadas práticas, costumes, profissões, lugares para se estar, formas de agir, estão diretamente relacionadas a um padrão único e hegemônico de ser humano.

Por ser a escola um espaço privilegiado para a promoção de questionamentos e aprendizagens não seria esse o lugar para a disseminação de reflexões quanto às relações de equidade e de poder? Ora, se nem todas as pessoas podem escolher quando e como atuar, se não podem influenciar politicamente nos mais variados âmbitos, se não encontram representação em profissões socialmente valorizadas, estariam vivendo em sociedades sustentáveis?

Ao que se pôde perceber nas falas dos (as) discentes na roda de conversa, ainda lhes parece difícil compreender que existem forças intrínsecas que atuam de maneira significativa sobre os que se encontram em uma sociedade capitalista.

E a fala da aluna que possui a compreensão de que existem lugares para brancos (as) e negros (as) estarem? Não seria uma denúncia ao que vem sendo promovido pela sociedade uma vez que a escola está inserida nessa primeira?

Que possamos pensar o quanto nossas práticas e nossos silenciamentos podem estar promovendo lugares e noções deturpadas de desenvolvimento.

\section{Referências}

BORDENAVE, J. E. D. O que é participação. São Paulo: Ed. Brasiliense, 1994.

FERNANDES, F. A integração do negro na sociedade de classes. 5 ed. São Paulo: Globo, 2008. 439 p.

GÓIS, J. B. H. Quando raça conta: um estudo de diferenças entre mulheres brancas e negras no acesso e permanência no ensino superior. Revista de Estudos Feministas. Florianópolis, v.16, n. 3, p. 743768, set./dez. 2008. Disponível em: <http://www.scielo.br/pdf/ref/v16n3/02.pdf>. Acesso em: 18 jun. 2017.

VEIGA, J. E. da. Desenvolvimento sustentável: o desafio do século XXI. Rio de Janeiro: Garamond, 2005. $163 \mathrm{p}$.

Recebido para publicação em 30/10/2017 e aprovado em 04/6/2018. 